\title{
Article \\ Solar-Hybrid Cold Energy Storage System Coupled with Cooling Pads Backup: A Step towards Decentralized Storage of Perishables
}

\author{
Anjum Munir 1,*, Tallha Ashraf ${ }^{1}$, Waseem Amjad 1,*(D), Abdul Ghafoor ${ }^{2}$, Sidrah Rehman ${ }^{1}$, Aman Ullah Malik ${ }^{3}$, \\ Oliver Hensel ${ }^{4}$, Muhammad Sultan ${ }^{5}$ (D) and Tatiana Morosuk ${ }^{6, *(D)}$
}

check for

updates

Citation: Munir, A.; Ashraf, T.; Amjad, W.; Ghafoor, A.; Rehman, S.; Malik, A.U.; Hensel, O.; Sultan, M.; Morosuk, T. Solar-Hybrid Cold Energy Storage System Coupled with Cooling Pads Backup: A Step towards Decentralized Storage of Perishables. Energies 2021, 14, 7633. https://doi.org/10.3390/en14227633

Academic Editor: Donato Morea

Received: 1 October 2021

Accepted: 11 November 2021

Published: 15 November 2021

Publisher's Note: MDPI stays neutral with regard to jurisdictional claims in published maps and institutional affiliations.

Copyright: (C) 2021 by the authors Licensee MDPI, Basel, Switzerland. This article is an open access article distributed under the terms and conditions of the Creative Commons Attribution (CC BY) license (https:/ / creativecommons.org/licenses/by/ $4.0 /)$.
1 Department of Energy Systems Engineering, University of Agriculture, Faisalabad 38000, Pakistan; talhaashraf313@gmail.com (T.A.); sidrareahman3@yahoo.com (S.R.)

2 Department of Farm Machinery and Power, University of Agriculture, Faisalabad 38000, Pakistan; abdul.ghafoor@uaf.edu.pk

3 Institute of Horticultural Sciences, University of Agriculture, Faisalabad 38000, Pakistan; malikaman1@uaf.edu.pk

4 Department of Agricultural \& Biosystems Engineering, University of Kassel, 37213 Witzenhausen, Germany; ohensel@uni-kassel.de

5 Department of Agricultural Engineering, Bahauddin Zakariya University, Multan 60800, Pakistan; muhammadsultan@bzu.edu.pk

6 Institute for Energy Engineering, Technische Universität Berlin, Marchstr. 18, 10587 Berlin, Germany

* Correspondence: anjum.munir@uaf.edu.pk (A.M.); waseem_amjad@uaf.edu.pk (W.A.); tetyana.morozyuk@tu-berlin.de (T.M.)

\begin{abstract}
Post-harvest loss is a serious issue to address challenge of food security. A solar-grid hybrid cold storage system was developed and designed for on-farm preservation of perishables. Computational Fluid Dynamic analysis was performed to assess airflow and temperature distribution inside the cold chamber. The system comprises a $21.84 \mathrm{~m}^{3}$ cubical cold storage unit with storage capacity of 2 tonnes. A hybrid solar system comprising $4.5 \mathrm{kWp}$ PV system, $5 \mathrm{~kW}$ hybrid inverter, and 600 Ah battery bank was used to power the entire system. A vapor-compression refrigeration system ( 2 tonnes) was employed coupled with three cooling pads (filled with brine solution) as thermal backup to store cooling $\left(-4{ }^{\circ} \mathrm{C}\right.$ to $\left.4{ }^{\circ} \mathrm{C}\right)$. Potatoes were stored at $8{ }^{\circ} \mathrm{C}$ for a period of three months (May 2019 to July 2019) and the system was tested on grid utility, solar, and hybrid modes. Solar irradiation was recorded in range of $5.0-6.0 \mathrm{kWh} /\left(\mathrm{m}^{2} \times \mathrm{d}\right)$ and average power peak was found to be $4.0 \mathrm{~kW}$. Variable frequency drive was installed with compressor to eliminate the torque load and it resulted about 9.3 A AC current used by the system with 4.6 average Coefficient of Performance of refrigeration unit. The average energy consumed by system was found to be $15 \mathrm{kWh}$ with a share of $4.3 \mathrm{kWh}$ from grid and $10.5 \mathrm{kWh}$ from solar, translating to $30 \%$ of power consumption from grid and $70 \%$ from solar PV modules. Overall, cold storage unit efficiently controlled total weight loss (7.64\%) and preserved quality attributes $\left(3.6{ }^{0}\right.$ Brix Total soluble solids, $0.83 \%$ Titratable acidity, $\left.6.32 \mathrm{PH}\right)$ of the product during storage time.
\end{abstract}

Keywords: solar cooling; post-harvest food losses; decentralized food storage; cooling pads

\section{Introduction}

Food security is a challenging task in developing countries, despite high production of food crops. It could be related to high post-harvest losses and uncertainty in agriculture and food policies of the governments. The seasonal character of agricultural produce is an important factor to be considered to save spoilage. Some fruits and vegetables are available for a short period of time in the year and need special care to stop their spoilage, especially when stored. Post-harvest losses exist due to lack of storage and transport infrastructures at a farm level and frequent power interruptions during food 
processing and handling [1,2]. Lack of the post-harvest processing facilities at farm level leads to spoilage of a significant quantity of perishable products. The most popular and conventional modes for the storage of perishables are drying and cooling [3-5]. The process of drying removes the moisture from the perishables; thus, the microbial activity decreases and spoilage of food is prevented [6]. However, the drying process changes the color, taste, and the texture of the product [7-10]. In case of cooling or freezing as a method of preservation, a product is stored at a low temperature to decrease the microbial activity. This process is used for the preservation of perishables effectively without product deterioration and shrinkage issues.

Conventional cold storage systems consume a large amount of energy for a refrigeration system. Due to their high energy consumption, it is not being readily adopted by the farming community. Moreover, commercial refrigerated plants (cold storages) are available only at large scale; they have a high capital cost and are not available in all areas, which translates into additional transportation cost [11]. Therefore, the "average" farmers cannot afford to store their products in those plants and must sell their product at low profit. In case of fruits and vegetables, the process of deterioration starts just after their harvest due to high product moisture content, heat of the field, improper handling, etc. [12,13]. To avoid such losses, timely storage is an economically best post-harvest technique. For this, decentralized (on-farm) cold storage facilities can significantly reduce losses and integration of such facilities with solar energy would reduce operational cost after payback period is over (usually 4-6 years). An experimental study on the thermodynamic design of alternate systems based on cold storage is reported in [14].

Considering these challenges in the agriculture sector, especially in developing countries, solar-based cold storage facilities for decentralized applications (on-farm) is a viable solution to reduce post-harvest losses in perishables. Use of solar energy for cooling is attractive due to comparative co-occurrence between solar irradiance and cooling requirement. Refrigeration and air conditioning systems operated by solar power have high potential in energy saving, which could reach 40-50\% [15]. The post-harvest losses of perishables are high in developing countries. Moreover, in tropical countries such as Pakistan, solar energy can be successfully used for various decentralized preservation and processing facilities where most of the villages have not access to grid supply. Considering Pakistan, it receives abundant solar radiations throughout the year [16]. There is an average of $5-7 \mathrm{kWh} /\left(\mathrm{m}^{2} \times \mathrm{d}\right)$ of solar irradiation available in most of the country and receives 19 MJ of energy on average throughout the year [17]. Therefore, solar energy would be a great alternative to the conventional grid system to run the cold storage facilities.

Although extensive work has been reported on refrigeration (types of systems, energy demand, etc.), little research has been done on the potential of solar energy for cooling, used materials, and storage options. Otanicar et al. [18] conducted a study of solar cooling in terms of economic and environmental impacts. It was concluded that one of the main hurdles in the extensive commercialization of solar cooling technologies is a high initial cost in case of standalone system due to the large size of battery backup, which decreases the competitiveness of these technologies. However, forecasts predicted that solar electric cooling would involve the least capital investment in 2030 because of the high COP values of vapor-compression refrigeration and high cost saving goals for PV technology. As the COP of refrigeration system is already high, coupling the refrigeration systems with efficient PV technology would, definitely, reduce operation cost. Thus, commercialization of solar cooling would be easy once PV technology becomes cheaper. An off-grid PV cooling system having two-stage energy storage (TSES) consisting of a battery bank and cold-water storage system has been proposed [19]. It was concluded that the key influence for battery capacity and capacity of cold storage system was a chiller schedule. A TSES system could increase the efficiency of the whole system by $6.73 \%$ and $10.27 \%$ based on single battery storage and single cold-water storage tank, respectively, under the most effective state in convex refrigeration capacity. A solar-powered cold storage system (6-8 tonne capacity) with battery backup and a vapor-compression refrigeration (2.5 TR) was reported in [20]. 
The system was able to maintain a temperature of $5-25{ }^{\circ} \mathrm{C}$ and a relative humidity of $65-95 \%$ inside the storage chamber. Although backup was provided, a battery bank cannot maintain required cooling conditions in case of prolonged cloudy weathers [20]. The use of a solar-based solar refrigerator (capacity of $150 \mathrm{~L}$ ) along with a thermal bank has been reported in [21]. For the cooling bank, a solution of distilled water and propylene glycol was used, which provided a freezing temperature below zero to $-10^{\circ} \mathrm{C}$ for approximately $16 \mathrm{~h}$. The performance of a solar biomass cold storage hybrid system is reported in [22]. This system is suitable for rural areas where biomass is present in a large quantity. No study has been reported on the decentralized use of solar energy in hybrid mode with cooling pads as a cooling backup, requiring less operational and maintenance cost in comparison to a system with a water-based cooling backup. Water-based cooling systems work on the maximum air conditioning load, leading to a very low efficiency once the machine is in idle mode. On the other hand, an air conditioning unit coupled with solar energy can be operated under low refrigeration capacity period, which helps to improve system energy efficiency [23].

Keeping in view the previous work reported, the potential of solar energy to be used for cooling and to provide a decentralized storage facility with thermal backup, a solar cold storage unit was designed and developed with a salient feature of its thermal backup (cooling pads, e.g., brine pads) for a time period of 36-48 h, depending on the ambient conditions. A sample product (potatoes) was stored for a period of three months (5 May 2019 to 30 July 2019). The system is operated on solar energy, but has an additional feature to be used in hybrid mode (operated on battery and grid). Moreover, this could be connected as a grid-tied or hybrid system in those areas where grid connectivity is available to improve efficiency and to decrease the operational cost of the system. To operate cold storage entirely on solar energy, during sun hours, some of the cooling from thermal pads is used to maintain the set cold storage temperature while the rest is consumed to maintain the brine solution at sub-zero temperature. Therefore, a temperature gradient always present between brine pads and cold storage chamber and cooling is transferred from brine pads to the product stored during night due to that temperature gradient. The research hypothesis is to develop a cold storage unit which can run continuously on solar energy for decentralized preservation of perishables by employing a solar grid hybrid system which automatically utilizes the full potential of available solar energy (as a first priority and switches to battery and utility to batteries or utility for extra energy demand if required) as well as using cooling as a backup source to store extra cooling produced by a cooling machine and maintain the quality of a stored product during storage time.

\section{Materials and Methods}

\subsection{Capacity and Size of Cold Storage Chamber}

The size of cold storage depends on the type and quantity of food to be stored, method of handling, and the dimensions of each basket/box used. Food is stored in baskets and these boxes are stacked on a pallet. The number of baskets, mass of food to be stored in a basket, and stacking of pallets depend on the type of food, storage time, and handling. Total capacity of the cold storage unit is calculated as:

$$
V_{C}=a_{f} h_{C}
$$

where $a_{f}$ is the area of the floor and $h_{c}$ is the height of cold storage chamber;

$$
h_{c}=h_{p}+c_{a}
$$

where $h_{p}$ is the height of each pellet and its value is $1.53 \mathrm{~m}$ and $c_{a}$ is the (vertical) clearance for aeration and its value was taken as $1.01 \mathrm{~m}$. The floor area of cold storage chamber $\left(a_{f}\right)$ is calculated by using Equation (3):

$$
a_{f}=n_{p} a_{p}+a_{s p}+a_{s w}+a_{s d}+a_{s e}
$$


where $n_{p}$ is the total no of pallets in cold storage chamber, $a_{p}$ is the area of one pallet (horizontal), and the product of $n_{p}$ and $a_{p}$ is also called net area required for the agri-product (which is equal to $3.11 \mathrm{~m}^{2}$ in this study), $a_{s p}$ is the space area between pellets (clearance space between each pallet is required for easy handling and proper air circulation; mostly inter pallet spacing is set to $75 \mathrm{~mm}$ ) and its value was $0.133 \mathrm{~m}^{2}, a_{s w}$ is the space area for walking/forklift etc. and its value was taken as $41.405 \mathrm{~m}^{2}, a_{s d}$ is the area of the space for door and its value was taken as $0.27 \mathrm{~m}^{2}$, and $a_{s e}$ is the area for the space for the evaporator and brine pads, which was $4 \mathrm{~m}^{2}$ in this study. The number of pellets $n_{p}$ are calculated as:

$$
n_{p}=\frac{m_{a g}}{m_{b} n_{b / p}}
$$

where $m_{a g}$ is the mass of agri-product to be placed in cold storage unit, $m_{b}$ is the mass of agri-product in one basket, and $n_{b / p}$ is the number of baskets per pallet (five baskets forms one pellet). For two tonnes $(2000 \mathrm{~kg}$ ) of agricultural products, the number of baskets were calculated to be 80 and the number pellets were calculated to be 16 using Equation (4).

By using Equations (1)-(3), the capacity of the cold storage unit was calculated to be $21.84 \mathrm{~m}^{3}$. A cubical cold storage unit $\left(21.84 \mathrm{~m}^{3}\right)$ was constructed with a length, width, and height of $3.657 \mathrm{~m}, 2.438 \mathrm{~m}$, and 2.438 respectively; this is sufficient to store two tonnes of the perishable products (potatoes). Polyurethane (PU) sheets (100 mm thickness) were used to construct cold storage room along with Prepainted Galvinized Iron (PPGI) metal faces of the walls to get better insulation. These metal faces were white in color to deflect the solar radiations and other heat sources to avoid temperature rise of the cold storage room. A PU door (Height: $1.83 \mathrm{~m}$; Width: $1 \mathrm{~m}$ ) was used to load and unload the agri-product as well as for the inspection of the product placed in cold storage.

\subsection{Refrigeration Capacity Calculations}

The size of the refrigerator depends on the volume of cold storage, mass, and type of food to be stored as well as time to reach the required temperature. While calculating the refrigeration capacity, all the sources of heat produced or heat losses (cooling losses from cold storage chamber, sensible heat addition of the loaded agricultural product, heat of respiration of the agri-product, heat produced due to human activity as well as heat due to light sand fans) were considered.

The heat transfer through the walls, roof, and floor was calculated by using Equation (5).

Figure 1 shows a 3D CAD and schematic of the developed solar cold storage unit. The entire solar cold storage system consists of three main subsystems named as cold storage system with cooling backup (brine pads), refrigeration system, and solar-hybrid system.

$$
Q_{T}=\frac{U A\left(T_{0}-T_{i}\right) \times 24}{1000}
$$

where $Q_{T}$ is the transmission heat load in $\mathrm{kWh} / \mathrm{d}, U$ is the thermal transmittance value of insulation in $\mathrm{W} /\left(\mathrm{m}^{2} \times \mathrm{K}\right), A$ is the surface area of the walls, roof, and floor in $\mathrm{m}^{2}, T_{i}$ stands for the air temperature inside the cold storage in ${ }^{\circ} \mathrm{C}$ or $\mathrm{K}$, and $T_{0}$ is the ambient air temperature in ${ }^{\circ} \mathrm{C}$ or $\mathrm{K}$.

The thermal transmission value of polyurethane insulation (100 $\mathrm{mm}$ thickness) was taken as $0.28 \mathrm{~W} /\left(\mathrm{m}^{2} \times \mathrm{K}\right)$, which was used in walls and roof with a total area of $38.65 \mathrm{~m}^{2}$, while the thermal transmission value of the floor insulation material was taken as $0.86 \mathrm{~W} /\left(\mathrm{m}^{2} \times \mathrm{K}\right)$ which was used in the floor. On average, a $28^{\circ} \mathrm{C}$ temperature change occurred lower down the inside temperature of the storage chamber at a set value. The total daily transmission load for the complete storage chamber was calculated as $12.426 \mathrm{kWh} / \mathrm{d}(7.27$ for walls and roof and 5.156 for the floor area) using Equation (5). The sensible heat load of the agri-product was calculated using Equation (6):

$$
Q_{P}=\frac{m \times c p \times\left(T_{\text {enter }}-T_{\text {store }}\right)}{3600}
$$


where $Q_{P}$ stands for the agri-product product load in $\mathrm{kWh} / \mathrm{d}, c_{p}$ is the specific heat capacity of the product in $\mathrm{kJ} /(\mathrm{kg} \times \mathrm{K}), \mathrm{m}$ is the mass of new products each day $(\mathrm{kg}), T_{\text {enter }}$ is the initial temperature of the entering agri-products in ${ }^{\circ} \mathrm{C}$ or $\mathrm{K}, T_{\text {store }}$ is the storage temperature of agri-products in ${ }^{\circ} \mathrm{C}$ or $\mathrm{K}$, and 3600 is the energy conversion factor from $\mathrm{kJ}$ to $\mathrm{kWh}$.

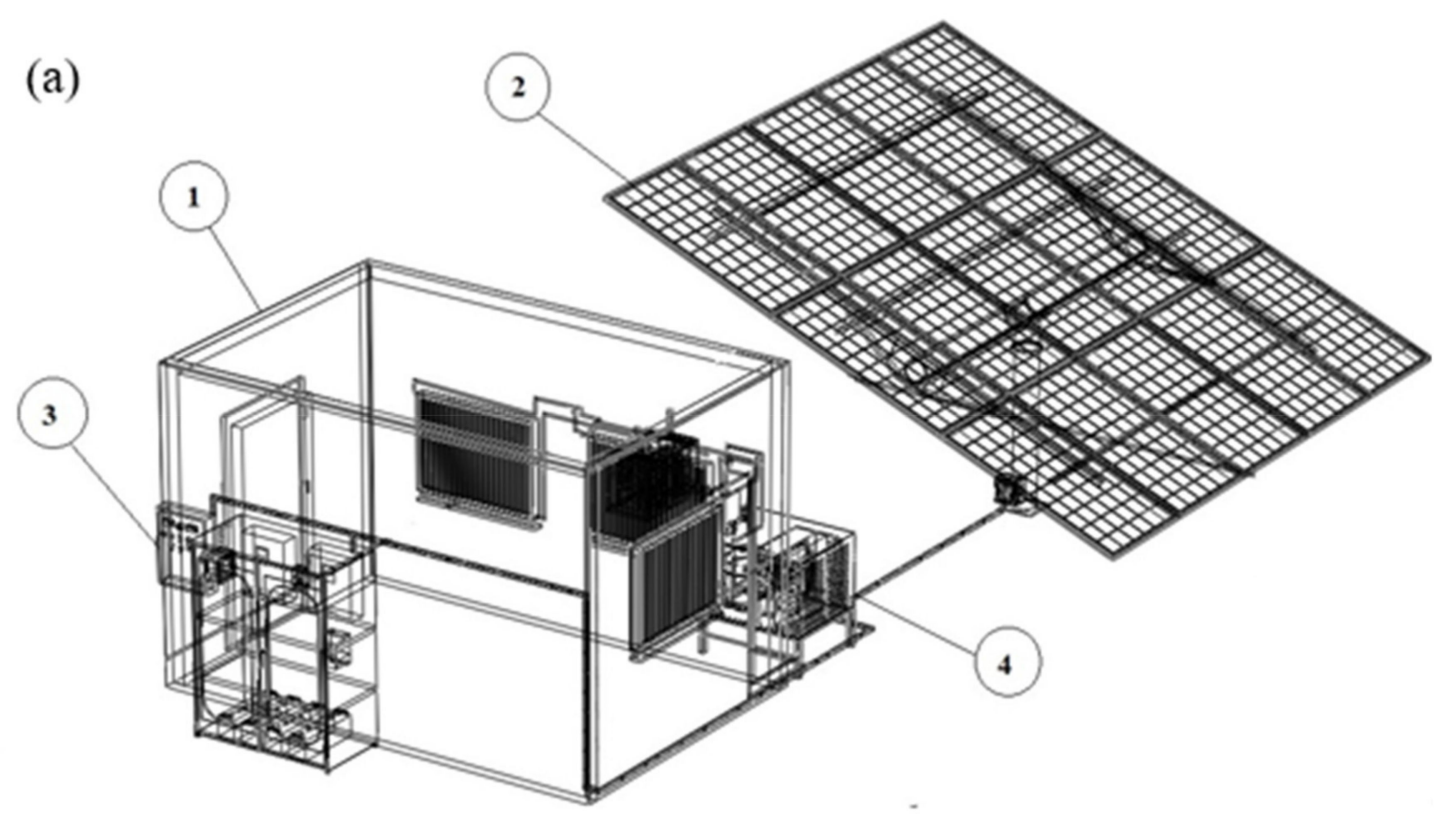

(b)

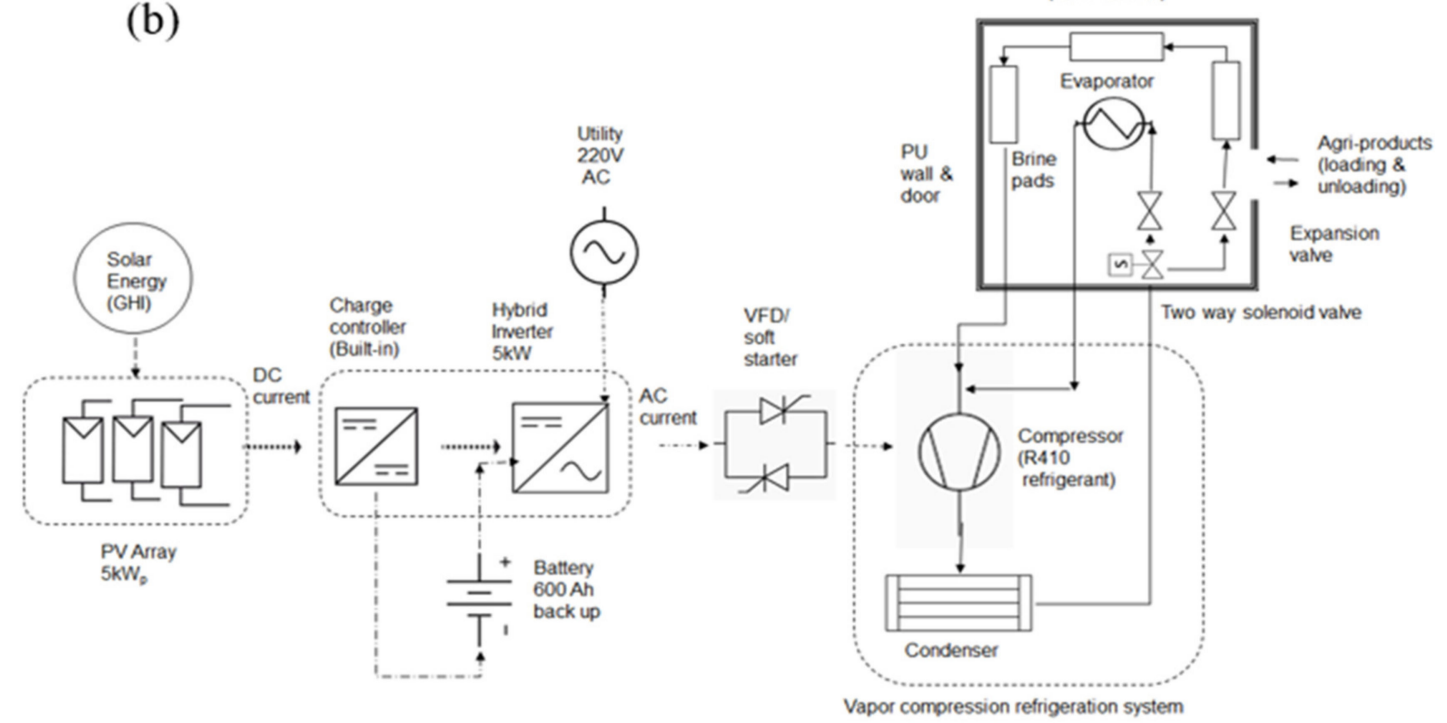

Figure 1. (a) 3D CAD of Solar Cold Storage System (1-storage chamber, 2-solar PV system, 3-monitoring and control system, 4-vapor-compression refrigeration system) and (b) schematic of solar cold storage system.

For the two tonnes $(2000 \mathrm{~kg}$ ) of agricultural product (potatoes) having specific heat of $3.43 \mathrm{~kJ} /(\mathrm{kg} \times \mathrm{K})$, the sensible refrigeration capacity was calculated to be $53.35 \mathrm{kWh} / \mathrm{d}$; nevertheless, this load is only required during the first day only while loading the cold storage unit. For the rest of the experiments, this component becomes equal to zero, but higher values will be considered during the designing phase. Respiration load of product was calculated as:

$$
Q_{R}=\frac{m_{a g} h_{r}}{24 \times 60 \times 60}
$$


where $Q_{R}$ is the respiration load in $\mathrm{kWh} / \mathrm{d}, m$ is the mass of product to be stored in storage in $\mathrm{kg}$, and $h_{r}$ stands for the respiration heat of the product in $\mathrm{kJ} / \mathrm{kg}$.

The respiration heat of the potatoes is $310 \mathrm{~kJ} / \mathrm{kg}$ and the respiration load for $2000 \mathrm{~kg}$ potatoes was calculated to be $7.17 \mathrm{kWh} / \mathrm{d}$. Internal heat loads of the persons working inside, the lighting, and the fans were calculated by considering the daily average heat produced and were found to be $6.0,0.3$, and $1.4 \mathrm{kWh} / \mathrm{d}$, respectively. The total heat load from all the sources (transmission heat load, sensible heat load, agri-product respiration heat load, workers heat load, lights and fan heat load) was calculated to be $81.126 \mathrm{kWh} / \mathrm{d}$ for storing $2000 \mathrm{~kg}$ of agri-products (postposes sample product) in cold storage unit. The theoretical refrigeration capacity (net refrigeration effect) was calculated to be $6.76 \mathrm{~kW}$ or 1.93 Tonnes of Refrigeration (TR) using $12 \mathrm{~h} / \mathrm{d}$ time of operation of the refrigeration unit for safe calculations. Thus, a refrigerator of 2 tonnes of refrigeration was used based on these calculations.

A vapor-compression refrigeration system, having a refrigeration capacity of 2 tonnes of refrigeration (TR) using R404a as a refrigerant, was installed. The refrigeration system consists of a compressor, condenser, expansion valve, and evaporator. Three cooling pads (brine pads) were used to provide cooling backup for operation during nighttime (no sunshine hours). Each brine pad has a $30.5 \mathrm{~m}$ copper refrigerant coil, which provides cooling from refrigerant to brine solution. The brine solution had a 1:2 concentration of $\mathrm{CaCl}_{2}$ with water and each cooling pad contains $75 \mathrm{~L}$ of brine solution. These pads store cooling equivalent to 0.65 tonnes of refrigeration while the refrigeration system is in operation and transfer cooling to stored product during operation at a rate of $2.275 \mathrm{~kJ} / \mathrm{s}$. Photographic views of the cold storage unit and brine pads are shown in Figure 2.

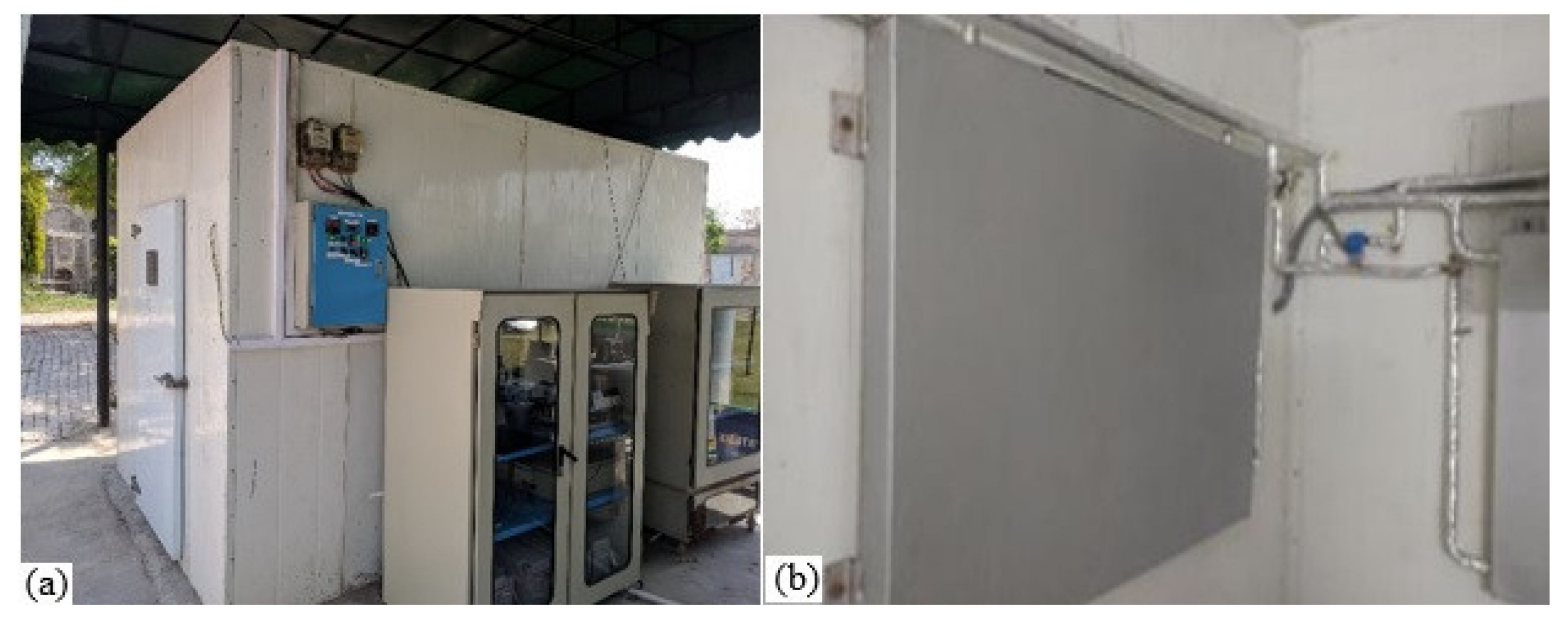

Figure 2. Photographic view of the solar cold storage unit. (a) Cold storage and data monitoring system and (b) inner view of the cold storage and the brine pads.

\subsection{Size of the Solar-Hybrid PV System}

The main advantage of using a hybrid solar system is the possibility of decentralized application to overcome the problem of power interruption and automatic switching to utilize solar energy to keep the system running with minimal battery backup. Unlike the grid-tied and standalone systems, a hybrid system does not require continuous supply of utility or a large-sized battery bank. Thus, a hybrid solar system was used in this study for the operation of the solar cold storage unit.

Peak power for the hybrid solar system $\left(P_{p}\right)$ in $\mathrm{kWp}$ for cold storage system is calculated as [24]:

$$
P_{p}=\frac{L_{e} I_{p}}{H_{a v g} \eta_{I} \eta_{B} T_{C F}}
$$


where $L_{e}$ stands for the electric load to operate the compressor, $\mathrm{I}_{\mathrm{p}}$ stands for the solar irradiance (peak) and for all the calculations, its value was taken $1 \mathrm{~kW} / \mathrm{m}, H_{\text {avg }}$ represents the average Global Horizontal Irradiance $\left(\mathrm{kWh} /\left(\mathrm{m}^{2} \times \mathrm{d}\right)\right)$, and the average value of GHI at the experimental site (Solar Park, University of Agriculture, Faisalabad, Pakistan; $\left.31.4456^{\circ} \mathrm{N}, 73.1356^{\circ} \mathrm{E}\right)$ was $5-6 \mathrm{kWh} /\left(\mathrm{m}^{2} \times \mathrm{d}\right)$.

For the calculation, the average value of GHI was taken as $5.5 \mathrm{kWh} /\left(\mathrm{m}^{2} \times \mathrm{d}\right), \eta_{I}$ is the efficiency of inverter (0.95-0.98) and has an average value of $0.965, \eta_{b}$ stands for the battery efficiency and has an average value of $90 \%, \mathrm{~T}_{\mathrm{CF}}$ stands for the temperature correction factor (0.92) and is calculated using the values of loss factor $\left(0.4 \%\right.$ per $\left.{ }^{\circ} \mathrm{C}\right)$, and the change in PV temperature at Nominal Operating Cell Temperature (NOCT) was taken as $45^{\circ} \mathrm{C}$. Standard testing conditions for crystalline Silicon were used. This means that power will reduce to about $0.4 \%$ for each increment in temperature from $25^{\circ} \mathrm{C}$ at standard testing conditions. By substituting all these values in the equations, the value of the PV peak was found to be $4.40 \mathrm{~kW}_{\mathrm{p}}$. For $4400 \mathrm{~W}$ power using $320 \mathrm{~W}_{\mathrm{p}}$ PV panels/modules, the number of panels were calculated to be 13.75. Practically, 14 numbers of solar PV modules were required to operate the system and, in this way, the total installed power of the system became $4480 \mathrm{~W}_{\mathrm{p}}$.

Normally, the size of the inverter should be 1.10-1.25 bigger than the product of peak power of the Solar PV array and the surge factor. Surge factor ranges from 1-3 depending upon the appliances used. In case of a soft starter of VFD, its value is taken as 1 . Thus, the theoretical value of the inverter was calculated as 4928 and a $5 \mathrm{~kW}$ inverter was used for this study, which was easily available on the market.

As the hybrid system is connected to the grid, the battery capacity $C_{b a t}$ in Ah required in this system is less than that of a standalone system, which is given by:

$$
C_{\text {Bat }}=\frac{P t_{\text {back }}}{D_{d} \eta_{b a t} V_{b a t}}
$$

where $D_{d}$ is the depth of discharge in fraction, $\eta_{b a t}$ is the battery efficiency, which ranges from 0.90 to $0.98, V_{b a t}$ is the nominal voltage of the battery, and $t_{b a c k}$ is the minimum backup time in hours of the appliances.

The solar-hybrid system consisted of solar PV modules, solar-hybrid inverter, battery backup, grid, and connection. A PV system of $4.5 \mathrm{~kW}_{\mathrm{p}}$ power was installed (14 PV polycrystalline modules with a peak power output of 320 watts each). These modules were connected to a hybrid inverter $(5 \mathrm{~kW})$ in two strings of seven modules per string, so the total solar output becomes $4480 \mathrm{~W}$. The hybrid inverter was also used to switch between grid and solar system depending on the availability. A battery backup of $600 \mathrm{Ah}$ capacity (four batteries of 150 Ah each with $12 \mathrm{~V}$ attached in series to form a 48 system compatible with the inverter) was also incorporated in the system to provide backup in case of electrical shortfall.

\subsection{Power Estimation}

The total power available from solar energy $\left(P_{s}\right)$ is basically the total energy or power (at a certain instant) available from the sunlight [25]. This value starts from zero early in the morning and reaches its peak at solar noon and then decreases to zero at sun set. The instantaneous value was calculated as:

$$
P_{s}=I_{s} A_{e} \eta_{m}
$$

where $I_{S}$ is the instantaneous value solar intensity or also called as Global Horizontal Irradiance (GHI), $A$ is the effective area of PV panels, and $\eta_{m}$ is the module efficiency.

The total power consumed by the cold storage $\left(P_{c}\right)$ is obtained as:

$$
P_{c}=0.9 A_{a c} V_{a c}
$$

where $A_{a c}$ is the current provided by the inverter, $V_{a c}$ is the voltage of the cold storage, and 0.9 is the power factor $(\mathrm{PF})$. 
The power utilized from the solar system $\left(P_{\text {um }}\right)$ was calculated as:

$$
P_{s}=I_{d c} V_{d c}
$$

The power utilized from the grid $\left(P_{g}\right)$ was calculated using Equation (13). The equations were used for load calculations during the experiments.

$$
P_{g}=P_{t}-P_{s}
$$

\subsection{Experimental Setup}

A data logger (Agilent 34970A) was used to record real time data through attached gadgets and sensors, as shown in Figure 3. For a complete performance analysis, experiments were conducted for a period of three months (5 May to 30 July 2019), under no load as well as under load conditions $(2000 \mathrm{~kg}$ ) using potato as the sample stored product. The cold storage system was operated on grid mode, solar mode, as well as on a hybrid mode (grid plus solar) to check the system performance and to compare energy consumption under different modes of operation. For this, SUB (solar-utility-battery) or SBU (solar-battery-utility) modes of hybrid inverter were set. A data logger (Agilent, 20 channel cartridge) was incorporated for real-time monitoring and data acquisition throughout the storage period. Several parameters were recorded, namely, solar irradiance, cold storage temperature, ambient temperature, compressor inlet temperature, compressor outlet temperature, expansion valve temperature, brine pads temperature, DC current provided by the solar PV modules, DC voltage of the solar PV modules, AC voltage of the solar-hybrid inverter, and the AC current provided by the inverter. For these parameters, thermocouples $\mathrm{K}$ type, error $<0.1^{\circ} \mathrm{C}$ ), hygrometer, Pyranometer (SP Lite; response type $<1 \mathrm{~s}$ ), and DC and AC voltmeters and ammeters were used and connected to data logger. For the assessment of product quality, one physical (weight loss) and three chemical (total soluble solids, titratable acidity, and $\mathrm{PH}$ ) quality parameters were measured at the end of the stored period.

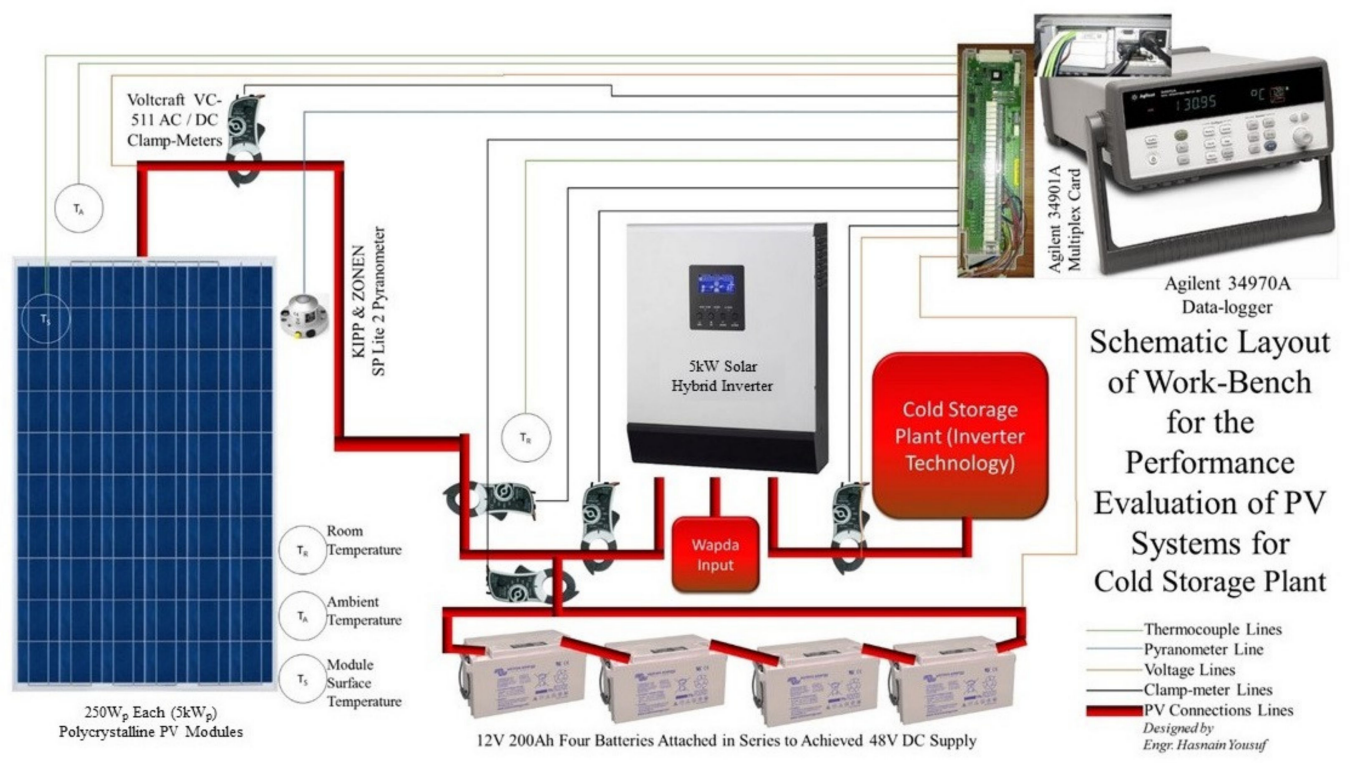

Figure 3. Schematic of the experimental setup.

\section{Results and Discussion}

\subsection{CFD Simulation}

Product weight loss, i.e., moisture loss during the storage period, is a result of mass transfer, which depends mainly on the heat transfer; thus, distribution of cold air (working fluid) inside the storage chamber is important [26]. For this, Computational Fluid Dynamics (CFD) software was used in ANSYS Workbench-18. It provides a comprehensive suite for 
modeling fluid flow and other related physical phenomena. As the profile of airflow and temperature distribution was of concern in the design assessment, only the influencing part of the system (cold storage chamber) was modeled and simulated. The purpose of the 3D model was also to assess flow variation and distribution in the depth of cooling chamber as well along with axial direction, which was not assessable in the 2D model. A 3D model was developed in ANSYS Design Modeler (number of elements: 65143, grid type: 3D, tetrahedral, structured). Wooden boxes and product within these boxes were modeled such that the chamber partially and completely filled with the product. The boxes were perforated from all the sides so that cooled air can thoroughly circulate through the product. The place of evaporator in actual design was taken as the inlet for cooled air to assign inlet boundary conditions (air velocity and temperature). As air has to pass through boxes, a turbulent flow regime was expected, and for this, a k- $\varepsilon$ standard turbulence model was applied along with a no-slip condition for the Wall friction model.

Figure 4 shows the profiles of the temperature and air distribution inside the cooling chamber. Cooled air enters into the cold chamber through an evaporator (inlet for the chamber) and circulates throughout the cold chamber uniformly, as can be observed from the velocity profiles (Figure 4c,d). It shows that the applied boundary conditions for inlet air were appropriate to overcome flow resistance due to product and buckets, for the uniform air distribution inside the chamber. The temperature distribution is linked with the air distribution. As soon as cooled air enters the chamber, it starts to exchange heat with the stored product to reduce its temperature. The difference in temperature of cooled air and the stored product can be observed in Figure $4 a, b$, which normally occurs during the early stages of the storage period. Products lying in front of the evaporator start to decease their temperature, which continues until all the products are at the same temperature. Air is continuously circulated inside the cold chamber and cools down through the evaporator to maintain the set stored temperature for the respective product.

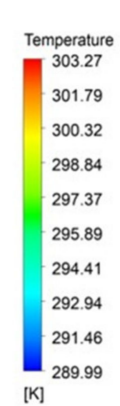

(a)

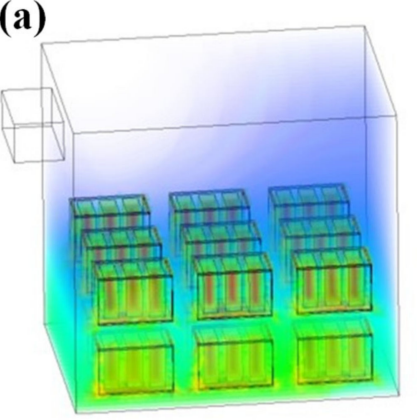

(c)

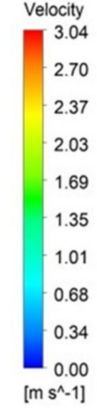

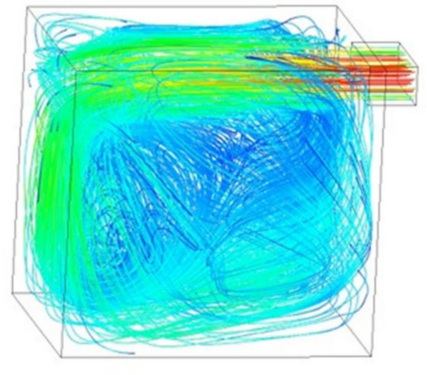
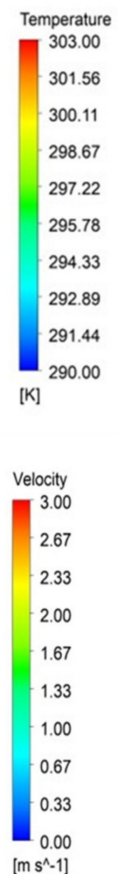

(b)

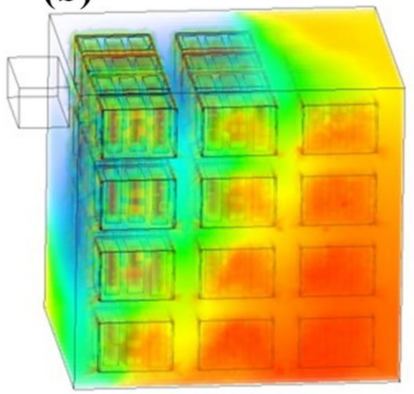

(d)

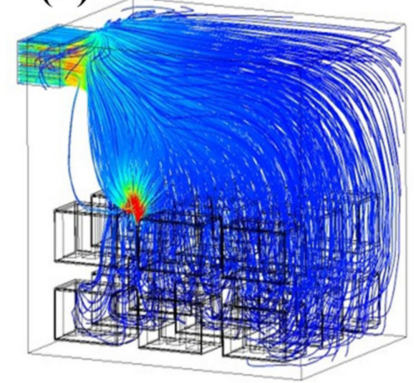

Figure 4. (a) Simulated profiles of temperature inside the cold storage chamber under partially loaded conditions and (b) fully loaded conditions. (c) Velocity distribution profiles inside the cold storage room under empty conditions and (d) partially loaded conditions. 


\subsection{Solar Irradiance Profile}

The developed cold storage system aimed to operate on solar energy; solar irradiance is an important parameter which needs to be investigated. The data for solar irradiance were monitored throughout the storage period. Figure 5 shows solar irradiance and total power available from sun for a sample representative storage time. The irradiance was measured using a Pyranometer which was mounted on the solar PV tracking stand parallel to the same plane of the PV panels.

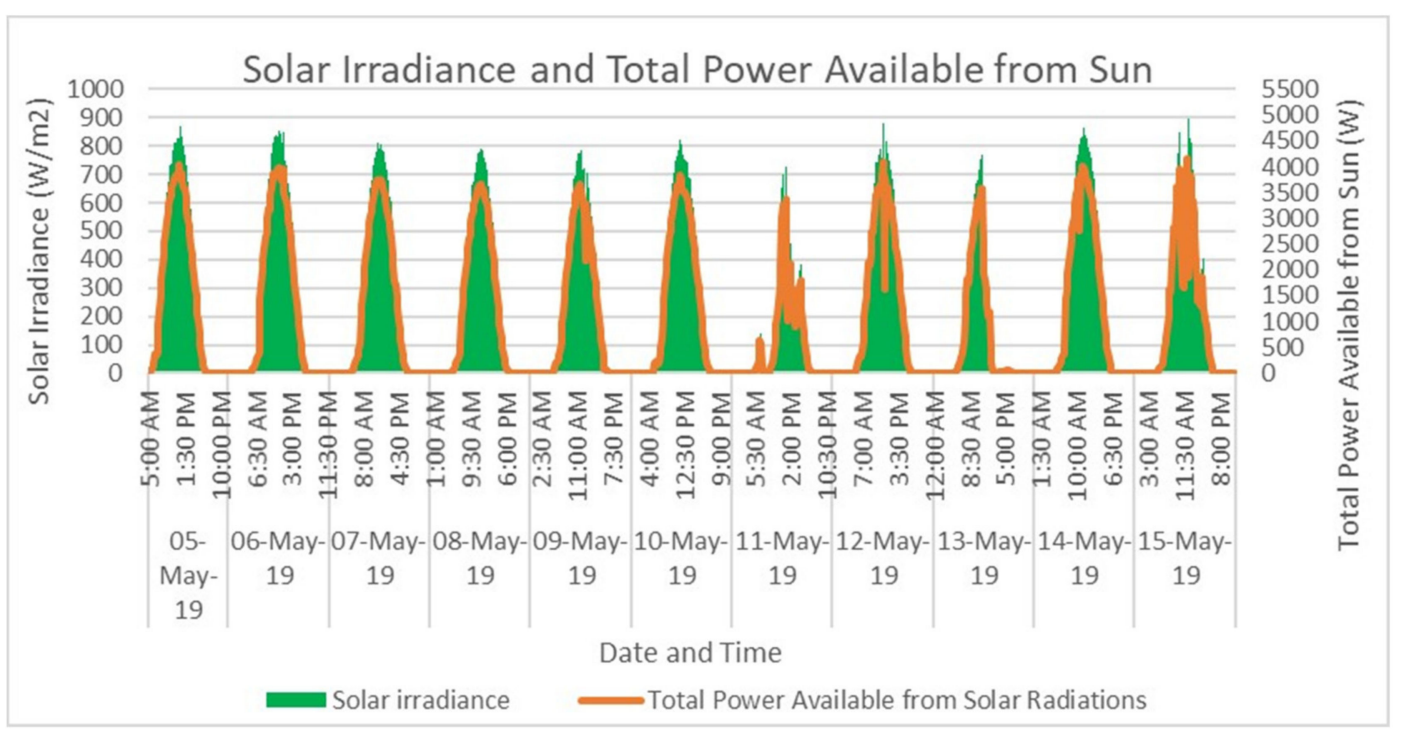

Figure 5. Solar irradiance and total power available from the sun.

It can be observed that values of solar irradiance remained nearly the same throughout the observed data. The data were recorded for three months (5 May 2019 to 30 July 2019) with the help of a data logger and the average value of solar irradiation was recorded between $5-6 \mathrm{kWh} /\left(\mathrm{m}^{2} \times \mathrm{d}\right)$ during the month of May and June, while the daily average was found to be $210-250 \mathrm{~W} / \mathrm{m}^{2}$. The solar irradiance was observed with a value of $700 \mathrm{~W} / \mathrm{m}^{2}$, while the highest peak solar irradiance was observed to be $897 \mathrm{~W} / \mathrm{m}^{2}$ during the experimental period. It was also observed that the about $4 \mathrm{~kW}$ power was available during the peak solar irradiance from the $4.5 \mathrm{~kW}_{\mathrm{p}}$ system. The solar irradiation available during the summer season irradiance and available power profiles show that sufficient solar energy is available at site to run the cold storage unit for the preservation of agricultural products.

\subsection{AC Current Profile}

The solar-based cold storage unit is designed in such a way that it can be operated on utility, solar, as well as on both options simultaneously to maintain the required storage conditions under adverse weather conditions. For this purpose, a hybrid inverter has been employed to switch at any mode on requirement, but the principal objective of the study was to run the cold storage unit on solar energy with a cooling/brine pad backup for night cooling. The research work started in different phases to optimize the system in steps. First, trials were made using a conventional vapor-compression refrigeration system running on a utility grid, as shown in Figure 6. 


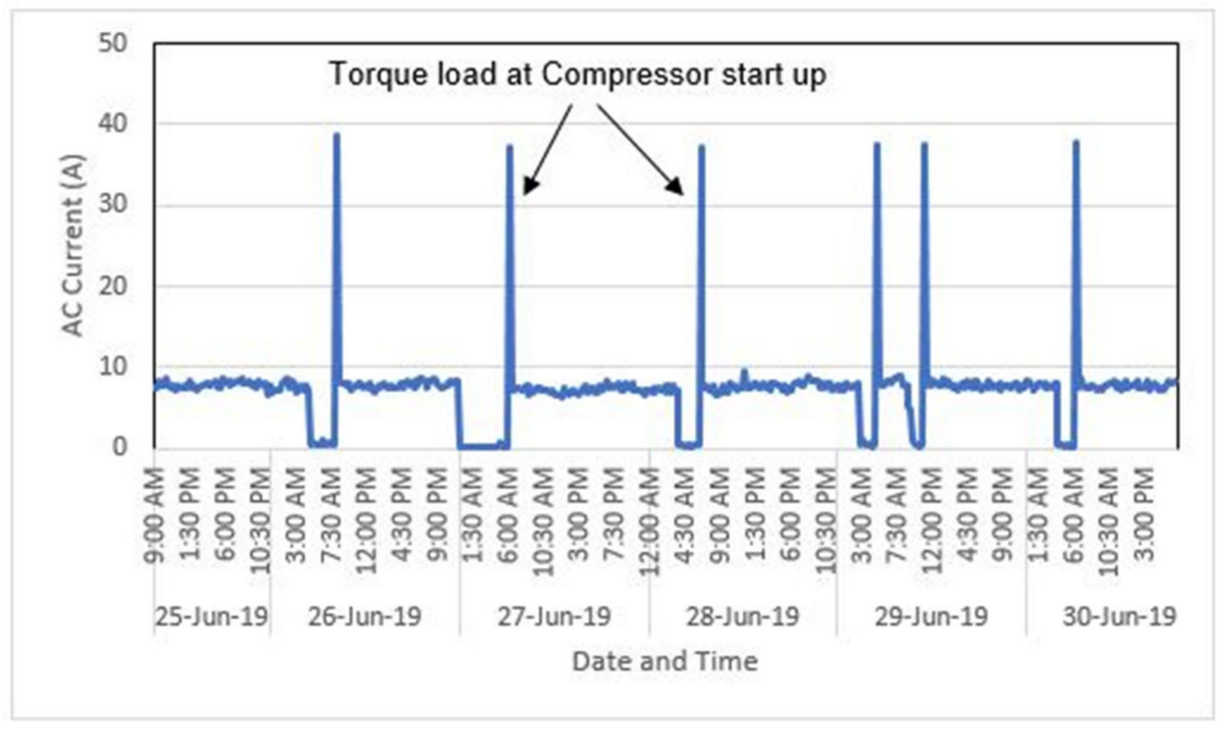

Figure 6. Variation of cold storage AC current (without VFD).

Figure 7 depicts the variation in cold storage AC current consumption during sample representative storage time. It can be observed that $\mathrm{AC}$ current dropped to zero when the compressor tripped down, mainly at nighttime when the cold storage temperature dropped to a set value. Thereafter, when the compressor restarted, a sudden surge in current can be seen in the figure. This surge current was due to torque load of the compressor [25]. This surge current is considered the main hurdle to run a cold storage system on solar energy. The surge current due to torque load could be reduced by employing a Variable Frequency Drive (VFD) or soft starter. The incorporation of VFD in the system enables the system to be operated entirely on solar PV system. Then, a VFD was incorporated in the system to reduce the surge current and variation in current (Amps), as shown in Figure 6.

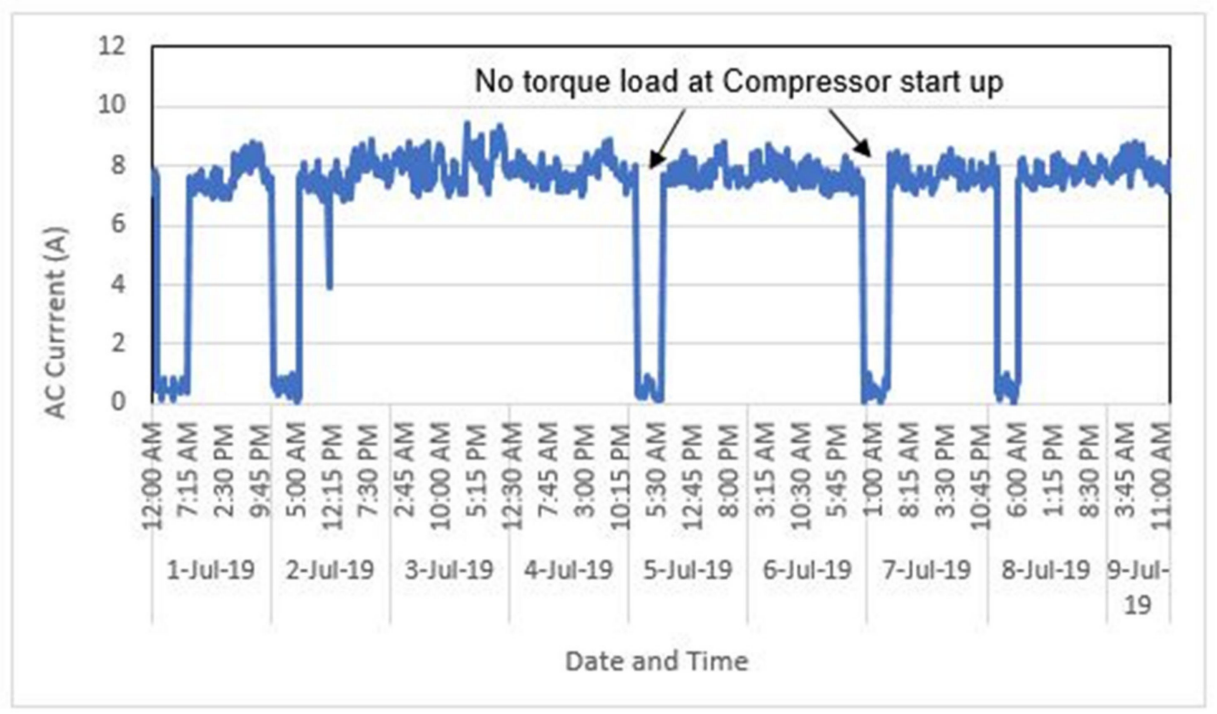

Figure 7. Variation of cold storage AC current (with VFD).

It can be perceived that there was no surge current when the compressor restarted after tripping. This is due to the application of VFD, which gradually increases the frequency of the compressor to the actual operating frequency, while keeping the AC current constant. The variation of the total available power and the power utilized from solar PV modules and grid with and without the application of VFD are demonstrated in Figures 8-10, respectively. 


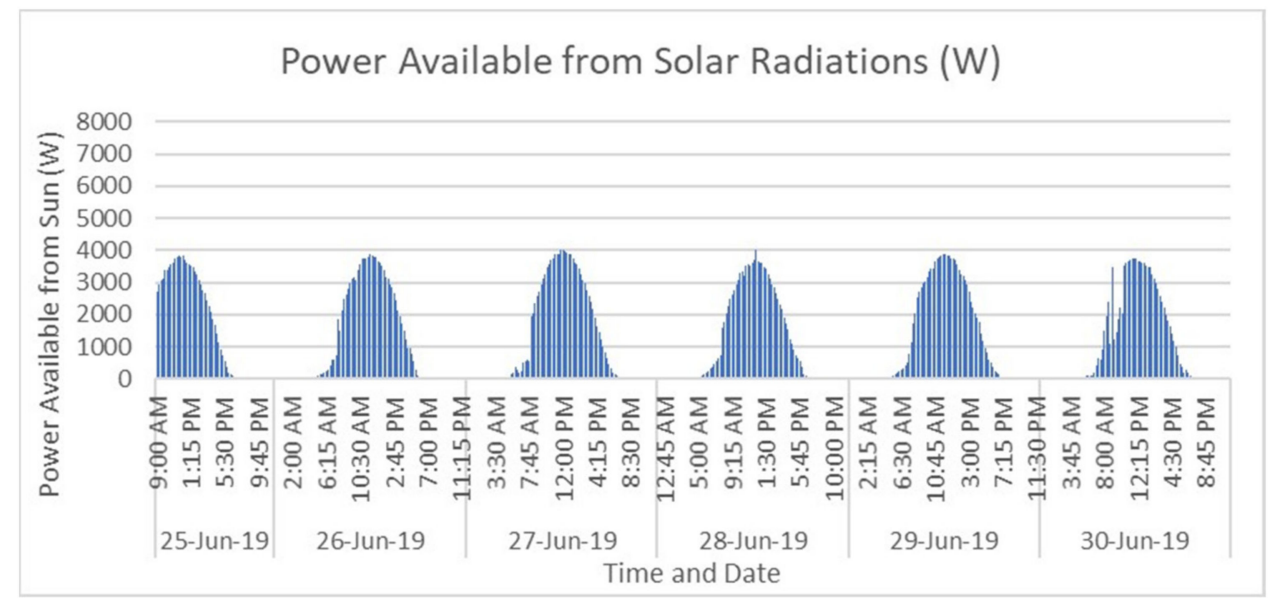

Figure 8. Variation of the power available from solar radiations.

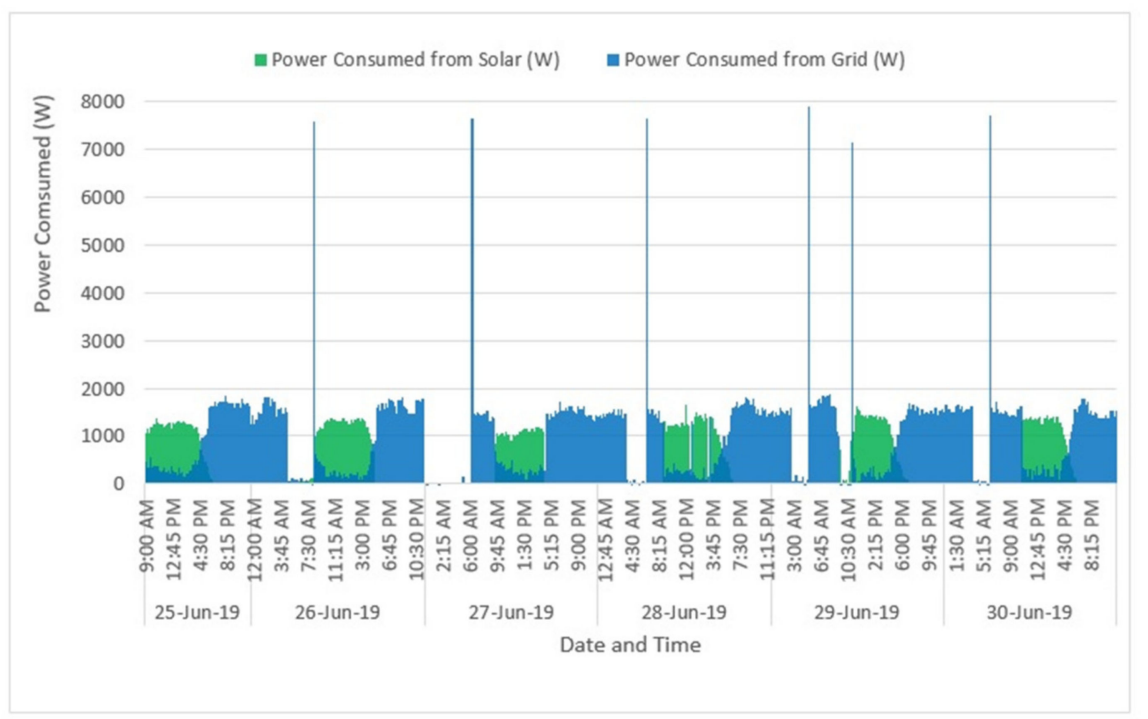

Figure 9. Power utilized from solar and grid (without VFD).

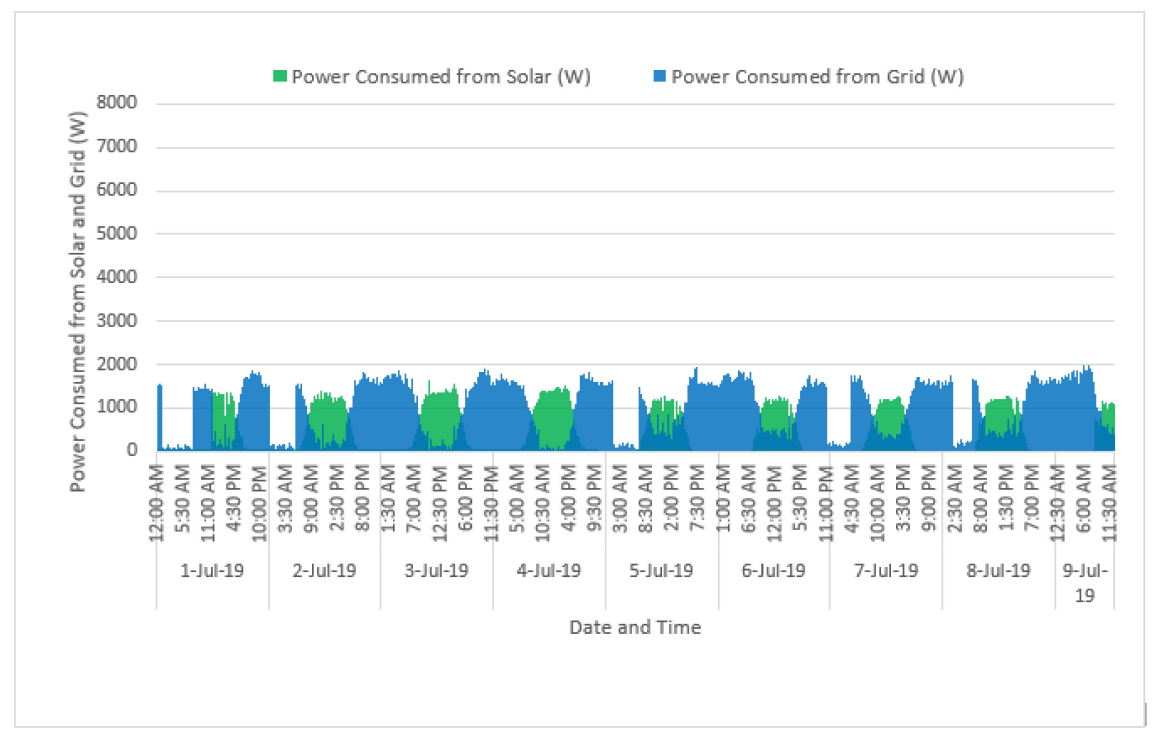

Figure 10. Power utilized from solar and grid (with VFD). 
It can be observed from Figures 8 and 9 that a lot of power available from solar radiations was not utilized by the cold storage system. The power available from solar modules went up to $4000 \mathrm{~W}$ (Figure 8), but the power utilized by cold storage was less than $2000 \mathrm{~W}$ (Figure 9). As the hybrid inverter only utilizes the DC current available from solar modules according to the power requirement of the attached load, the remaining portion of power is wasted and not utilized properly. That wasted power could be harnessed by utilizing the grid-tied inverter and the energy could be sold to the grid by net-metering or by employing a battery bank to store the extra energy when required. From the Figures 9 and 10, a surge in power can also be observed. This is due to the surge current produced by the torque load of the compressor. From Figure 9, it can be observed that the power to compensate the surge current due to torque load of the compressor was obtained from the grid, as the solar system was not sufficient to generate that amount of power. Therefore, the system was unable to be operated solely on solar PV power. The problem was resolved by installing VFD, which controlled the torque load of the compressor (Figure 10). This device gradually increases the frequency of the compressor while keeping the current constant at the normal operating range. Due to this reason, the surge current avoided and the compressor started at normal operating current as shown in Figure 10. It can be observed that the surge in power was minimized with VFD. The peak power requirement at torque load without VFD was $7800 \mathrm{~W}$ (Figure 9), which reduced to $1800 \mathrm{~W}$ (Figure 10) after the installation of VFD, translating into $77 \%$ power saving which was consumed during the surge load of the compressor. After installation of VFD, the system became feasible to be operated solely on the solar PV power, which was the core objective of the current study. The decentralized application of the cold storage system is only possible when it could be operated on the solar PV system, as there is uncertainty in the grid at farm level.

\subsection{Operation of a Cold Storage Unit Using Cooling Pads as Backup}

The key objective of the current study was to design and develop a cold storage unit operated on solar energy, and to do so, the addition of cooling pads was one of the tasks to enable the system to maintain storage chamber temperature at nighttime storage. A $5 \mathrm{~kW}_{\mathrm{p}}$ was enough to run the compressor integrated with VFD to eliminate the torque load during daytime sunny conditions. A 600 Ah battery backup (using $12 \mathrm{~V}$ and provides $3.6 \mathrm{kWh}$ energy at $50 \%$ depth of discharge) is sufficient to ensure the continuous operation of a cold storage unit for approximately two hours during partially cloudy condition or during nighttime. One of the principal advantages of developing the solar cold storage unit is that the higher and lower energy demands in summer and winter are automatically met with the seasonal sunlight fluctuation; higher in summer (solar irradiance: 700-1000 and solar irradiation: $5.5-7.0 \mathrm{kWh} /\left(\mathrm{m}^{2} \times \mathrm{d}\right.$ ) and lower in winter (solar irradiance: $500-700 \mathrm{~W} / \mathrm{m}^{2}$ and solar irradiation: 4.0-5.5). This best energy match evolved the idea of solar cold storage system. In addition to cooling pads, an evaporator fan is also employed for uniform cooling during day and nighttime and can be run on demand. During functioning, the system automatically runs when the irradiance is high enough to run the compressor. In this way, the cold storage system automatically starts cooling inside the cold storage chamber. As the intensity of solar radiation increases, it lowers the temperature of brine pads automatically throughout the day and the cooling is distribution to the products inside the brine pads. Additionally, the battery is charged with additional energy to get ready for electricity backup in case of solar fluctuation. Figure 11 explains the cooling profiles of the cold storage plant (shown by bars) operated on the cooling coil (curve shown by the line diagram) during a trial of two days (readings were recorded with the help of a data logger).

During the nighttime, the lower temperature of brine pad automatically transfers the cooling to the products placed for the preservation, and hence, the temperature of brine pads starts increasing during the evening and nighttime. The perfect insulation of polyurethane used for the structure (walls, roof, door, and the floor) of the cold storage unit and lower temperature during the nighttime ensure that the temperature does not 
increase too much, and cold temperatures are successfully stored in bthe rine pads during sunny hours to maintain the cold storage temperature. The detail of two days trials (from 9:15 to 19:00 h) has been shown in Figure 11.

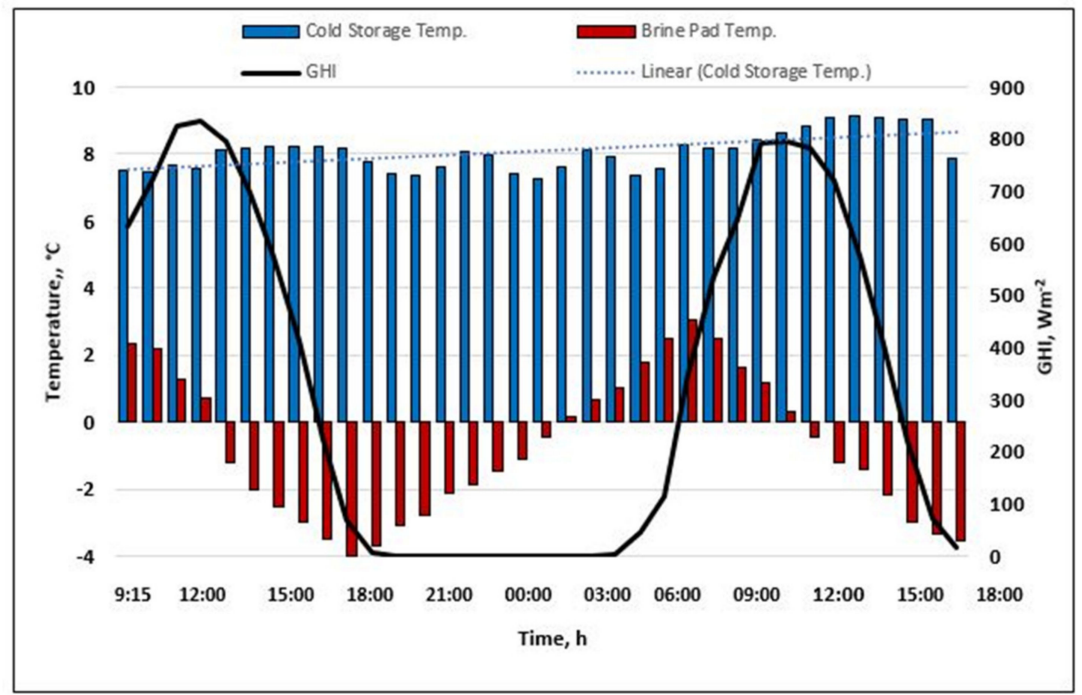

Figure 11. Temperature profiles of cold storage chamber and cooling pads (14-15 May 2019).

It has been observed that the cooling pads temperature decreases during daytime along with the cooling provided to the cold storage unit. During nighttime, this cooling is utilized to cool the cold storage unit at storage temperature using temperature differential. This trial was successfully run for potatoes where storage temperature requirement was $8{ }^{\circ} \mathrm{C}$. For other products which have storage temperature less than this figure $\left(8^{\circ} \mathrm{C}\right)$, a battery backup can be utilized during the nighttime if required without compromise on storage temperature and the quality of the products. For the trials with potatoes, the relationships between $\mathrm{AC}$ current and $\mathrm{AC}$ voltage and DC current and DC voltage versus time are drawn simultaneously for day and night times in Figure 12. It is evident that the cold storage unit used solar energy to maintain the cooling inside the storage chamber and also charged the cooling pads for nighttime operation, while no electricity was consumed from any source during the nighttime, as the cooling pads were sufficient to maintain the storage temperature.

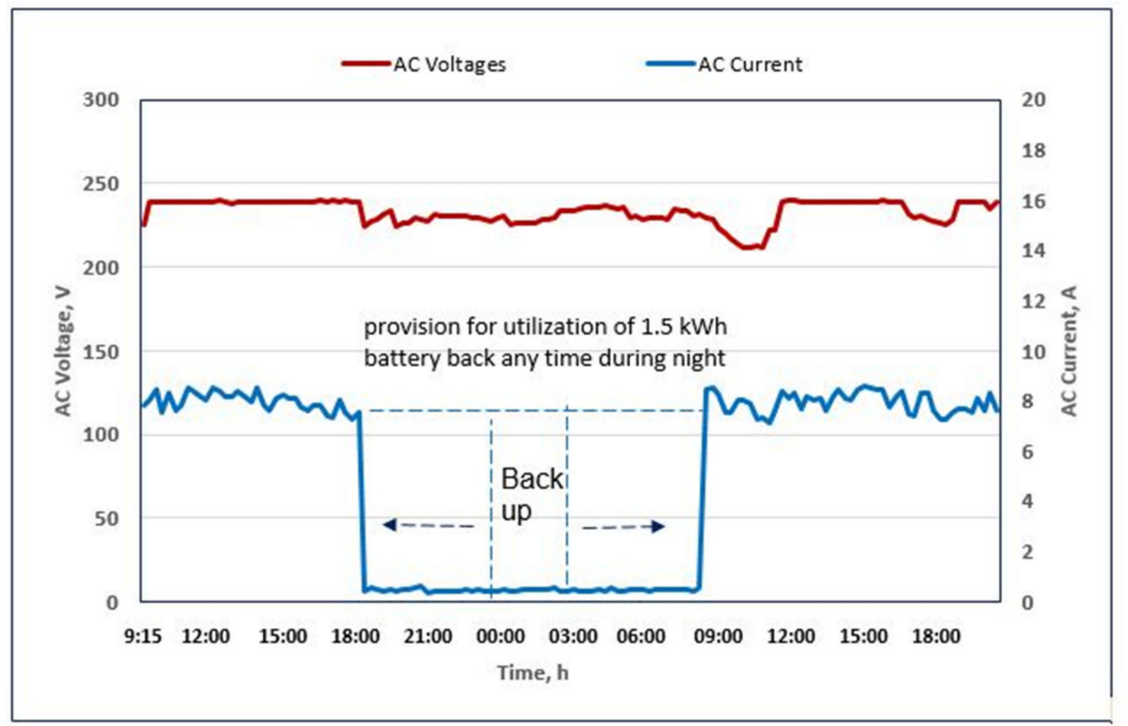

Figure 12. Relationships between AC current and AC voltage and DC current and DC voltage versus time (14-15 May 2019). 


\subsection{Relation between the Cold Storage Temperature and Relative Humidity}

The inside temperature of a cold storage chamber is the most crucial parameter for the safe storage of perishable food items. Moreover, relative humidity is also a very important parameter and it should be maintained above $80 \%$ for the preservation of perishables. The set temperature of the cold storage depends on the product stored in the cold storage. In the current experiment, potatoes were used as stored product and the optimum temperature for storing potatoes is $7-8{ }^{\circ} \mathrm{C}$. Therefore, the cold storage temperature was set to $7{ }^{\circ} \mathrm{C}$ throughout the experiment. Figure 13 shows temperature and humidity profiles within the cold storage chamber during a sample representative storage time. It can be observed clearly that the storage temperature was maintained at a set value, and the relative humidity was also above $80 \%$.

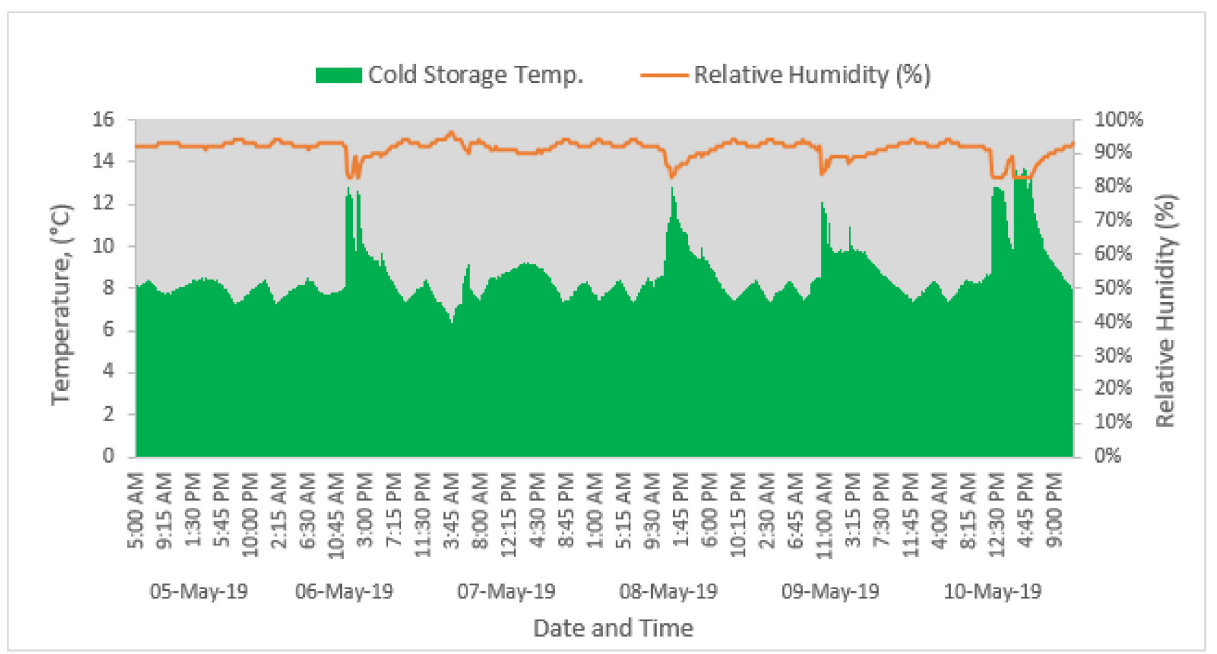

Figure 13. Variation in the cold storage temperature and relative humidity.

\subsection{Cold Storage Temperature and Brine Pad Temperature}

For cooling backup, three cooling pads were installed inside the cold storage chamber. The temperature of the cooling pads is usually less than $0{ }^{\circ} \mathrm{C}$, although it varied to keep the cold storage temperature constant. Figure 14 shows the temperature variation in the cooling pads and storage chamber to assess the contribution of the cooling pads while maintaining storage temperature. This figure shows the data for a trial of one week where battery and utility were also used when required. It can be observed that the cold storage temperature remained $8{ }^{\circ} \mathrm{C}$ for most of the storage time, while brine pads temperature varied in range of $-4{ }^{\circ} \mathrm{C}$ to $4{ }^{\circ} \mathrm{C}$. The rise in the cooling pads temperature was because of the fact that the cold storage temperature increased due to some activity (e.g., opening of the door) and the cooling pads in turn counteract to reduce the change in temperature by providing cooling to the storage space to maintain the set temperature.

\subsection{Coefficient of Performance (COP)}

A vapor-compression refrigeration unit was installed in the system. The COP of the refrigeration system is the most important parameter for the performance evaluation of refrigeration system [27]. The COP is basically the ratio of output of refrigeration system to the input provided. The COP of Vapor-compression Refrigeration System is calculated by the ratio of change in enthalpies. The formula for calculation of COP is given by Equation (14):

$$
\mathrm{COP}_{R}=\frac{h_{1}-h_{f 3}}{h_{2}-h_{1}}
$$

where $h_{1}$ is the vapor enthalpy of refrigerant before entering the compressor (average value $=361.4 \mathrm{~kJ} / \mathrm{kg}$ ), $h_{2}$ is the vapor enthalpy of refrigerant after the compression (average value $=386 \mathrm{~kJ} / \mathrm{kg}$ ), and $h_{f 3}$ is the liquid enthalpy of the refrigerant after leaving the 
condenser (average value $=247.9 \mathrm{~kJ} / \mathrm{kg}$ ). Those enthalpies were tabulated by comparing the corresponding temperatures from enthalpy sheet of R404a refrigerant gas. The average COP of the system throughout the week was approximately 4.61 .

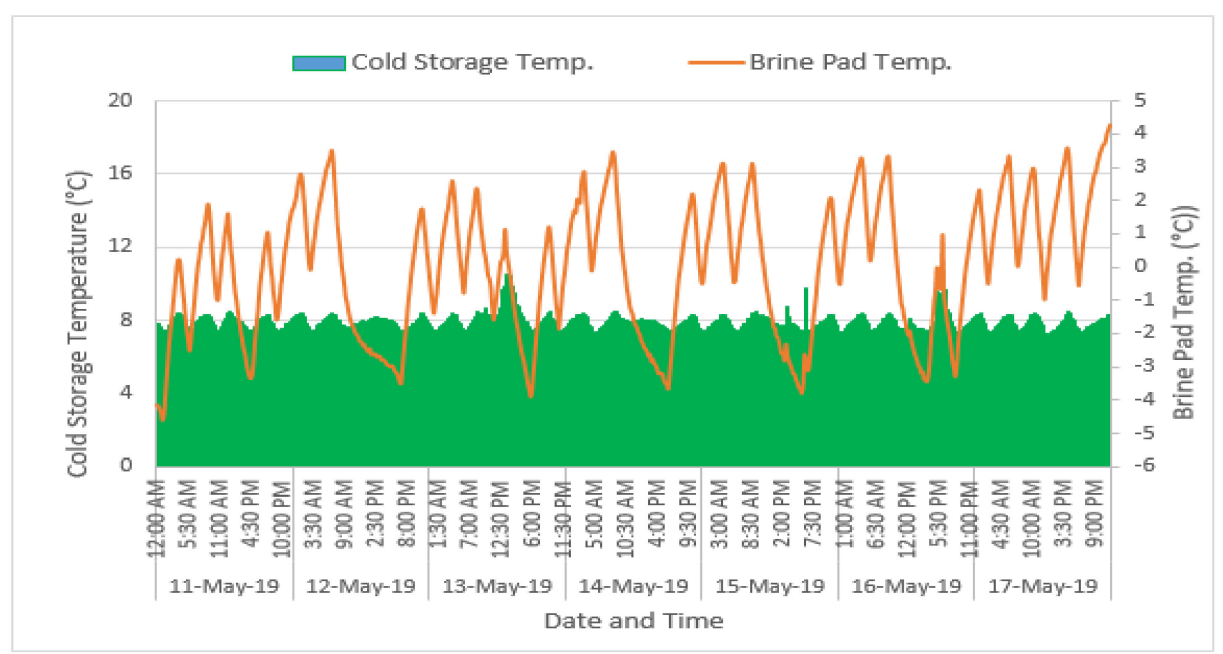

Figure 14. Variation in the cold storage temperature and brine pads temperature.

\subsection{Energy Consumed}

Energy consumption is a major parameter for the operation of a cold storage system. Considerable saving in the energy is possible through optimization of cold storage operation in terms of heat loads and the operation of the refrigeration system [28]. Energy meters were used to measure the daily energy consumption. The daily consumed units or $\mathrm{kWh}$ of energy were recorded, and the total energy consumption of 10 days were observed. Figure 15 shows energy consumption of the cold storage. It can be observed that the minimum units utilized by the cold storage were $10 \mathrm{kWh}$ and the maximum utilized units were $19 \mathrm{kWh}$. The average units consumed were $15 \mathrm{kWh}$. Meanwhile, the average $\mathrm{kWh}$ consumed from grid and solar were $4.3 \mathrm{kWh}$ and $10.5 \mathrm{kWh}$, respectively, which translates to $30 \%$ of power consumption from the grid and $70 \%$ from the solar PV modules.

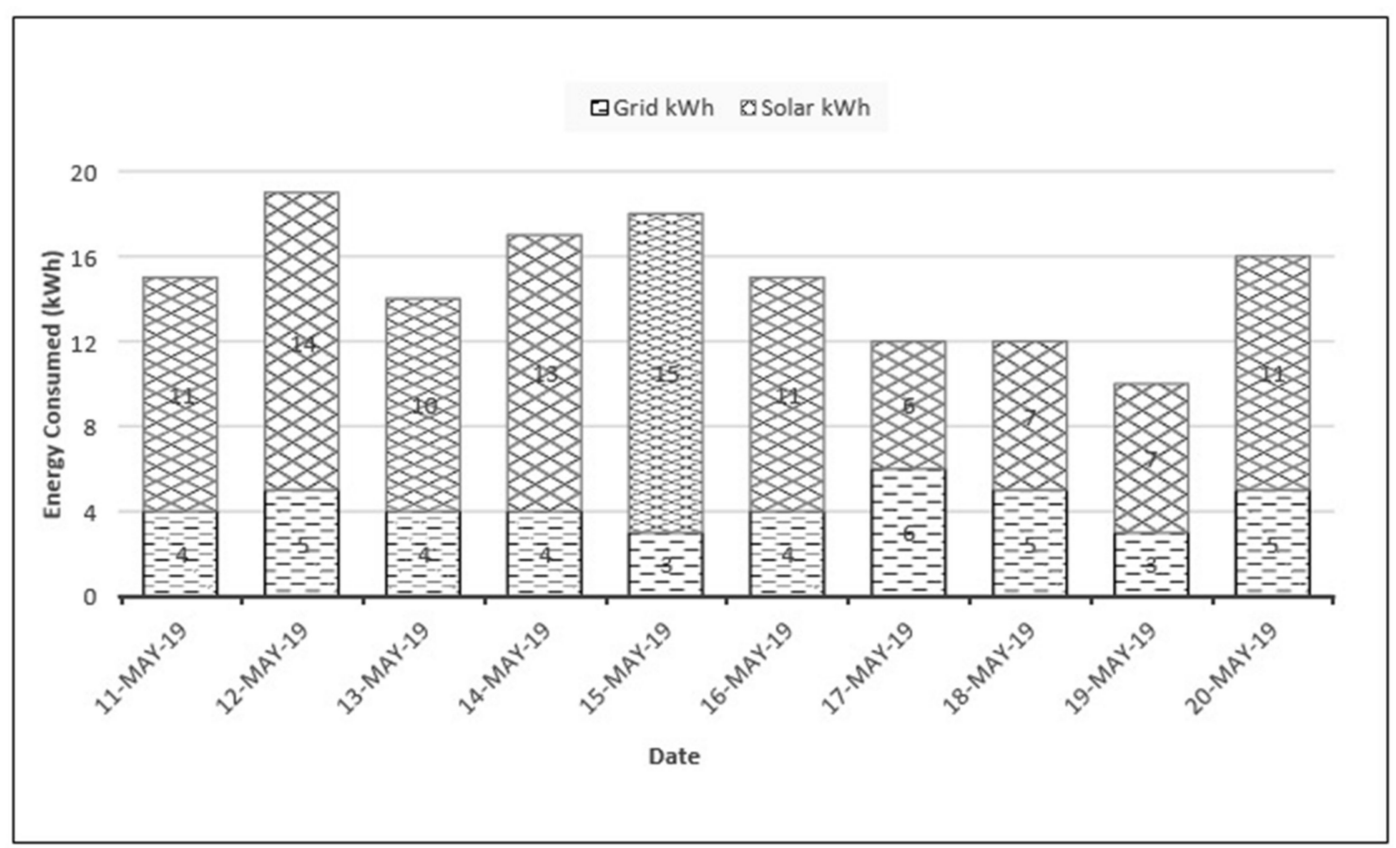

Figure 15. Energy consumed by the solar cold storage. 


\subsection{Effect of the Cold Storage on Potato Weight Loss and Quality}

The effectiveness of cold storage was also demonstrated through measuring its efficiency in terms of quality preservation of stored potato. For this purpose, potatoes stored in cold storage for three months (5 May 2019 to 30 July 2019) at $7 \pm 1{ }^{\circ} \mathrm{C}$ were evaluated for weight loss and other quality parameters, at fortnightly intervals. Quality assessments were carried out at Postharvest Research and Training Centre, Institute of Horticultural Sciences, UAF. Weight loss was measured by taking the total weight of eight buckets (initially $25 \mathrm{~kg}$ each) and calculated as the percentage of weight loss [29]. Total soluble solids were recorded by using a digital refractometer (ATAGO Co. Ltd., Minato-ku, Tokyo, Japan) and expressed as ${ }^{0}$ Brix. The titratable acidity of potato was estimated from extracted juice, as detailed by Malik et al. [30]. The $\mathrm{pH}$ of potato pulp juice was measured by a benchtop digital $\mathrm{pH}$ meter (HI98130-Hanna Instruments Inc. Romania). Results are shown in Figure 16.
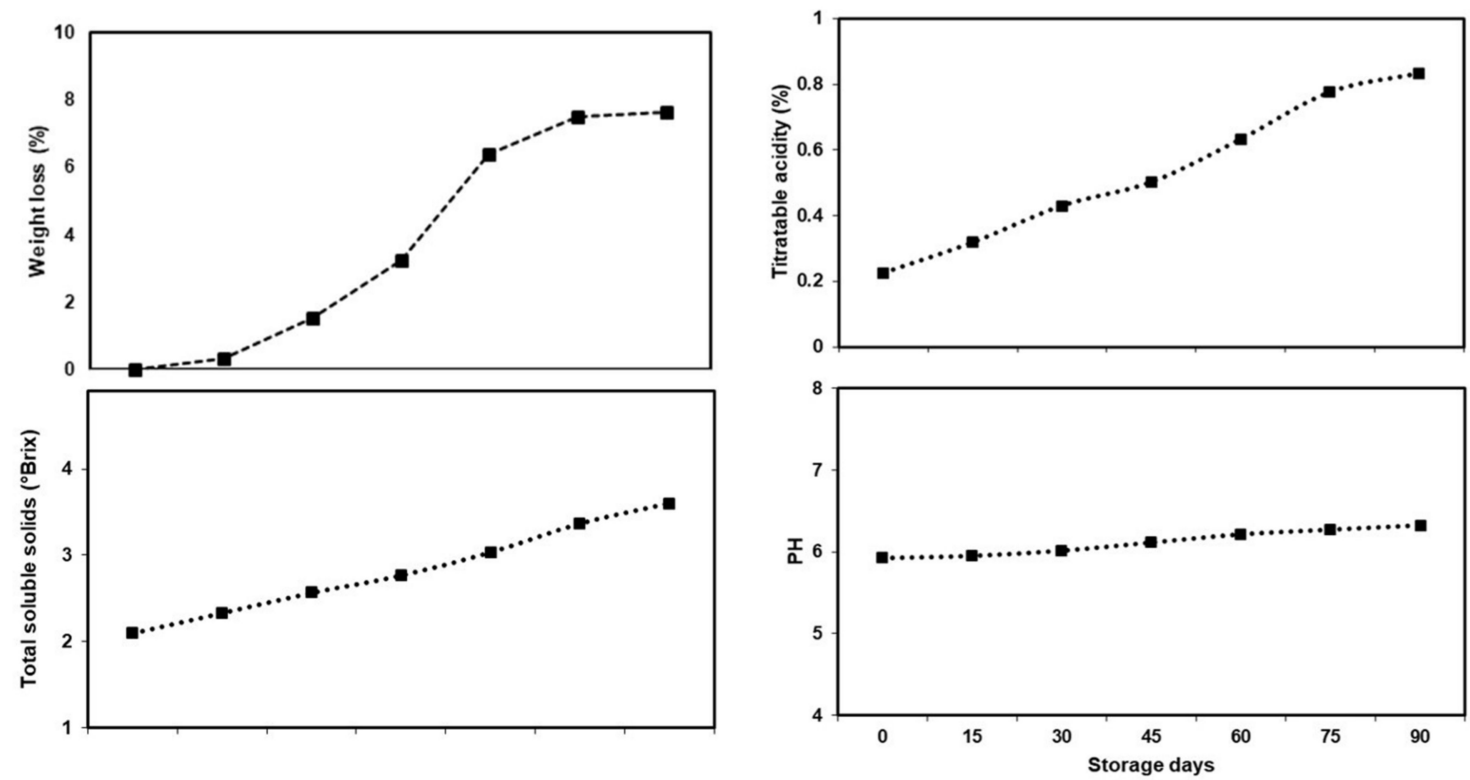

Figure 16. Effect of cold storage on weight loss and various quality parameters of stored potatoes.

As shown in Figure 16, potato weight loss was $0.32 \%$ after the first 15 days, and $1.53 \%$ in the first month. The total weight loss over three months was $7.64 \%$. In a previous study, Khurana et al. [31] reported that out of 11 potato cultivars stored, three cultivars had less than $10 \%$ weight loss, while eight cultivars had more than $10 \%$, with an overall range of $8 \%$ to $23 \%$. Thus, the total weight loss $(7.64 \%)$ in the current study is lower/in range with comparison to the product stored in a grid supply centralized cold storage facility showing the effectiveness of cooling of the developed unit during the product storage time. Total soluble solids (TSS) showed the conversion of starch to sugar content in potato. At day 0, the TSS was $2.1^{0}$ Brix, which increased gradually in storage, reaching $3.6^{0}$ Brix at the end of storage. These results are in line with the potato storage study by Khurana et al. [32]. Titratable acidity (TA) mostly affects the $\mathrm{pH}$ of the product. At the start of the experiment, the titratable acidity of the potatoes was $0.22 \%$, which increased as storage proceeded, finally reaching $0.83 \%$. The $\mathrm{pH}$ is used to measure the acidity or basicity of the solution or food product. At day 0 , the $\mathrm{pH}$ of the potatoes was 5.92, which slightly increased, reaching 6.32 at the end of the experiment. Overall, in this experiment, cold storage efficiently controlled weight loss and preserved potato quality, demonstrating its cooling efficiency.

\section{Conclusions}

The current study was conducted to develop a solar-grid hybrid cold storage system for on-farm storage of perishables to reduce post-harvest losses at production sites. The 
main body of cold storage room was made of polyurethane material (100 mm thick) to minimize the heat load. The system is operated on solar energy, employing a solarhybrid inverter with a battery and utility backup to run the system in case of adverse weather conditions. As a backup source, cooling pads were used to provide cooling during nighttime and system took approximately $9-12 \mathrm{~h}$ to reach set temperature of $7{ }^{\circ} \mathrm{C}$ from $25^{\circ} \mathrm{C}$ when operated on cooling pads. These pads maintained the temperature of the cold storage chamber for more than $12 \mathrm{~h}$ with a $5^{\circ} \mathrm{C}$ rise in temperature in $24 \mathrm{~h}$. The system is capable to meet higher and lower energy demand in summer and winter automatically with the seasonal sunlight fluctuation. The use of a variable frequency drive (VFD) with a compressor saved 77\% energy comparative to energy consumed without installing VFD. Due to hybrid nature of the system and its priority to use the full potential of the available solar energy, $70 \%$ of the consumed energy was shared from solar PV modules. Effective utilization of solar energy with enough cooling backup and minimum dependency on grid utility made the system energy efficient and enabled it to store product without deterioration (total weight loss was $7.64 \%$, TSS increased from $2.1{ }^{0}$ Brix to $3.6{ }^{0}$ Brix, and TA increased from $0.22 \%$ to $0.83 \%$, while the $\mathrm{pH}$ was 5.92 to 6.32 at the end of the experiment). Based on the outcomes, the following conclusions were drawn:

- The research concluded that 2 tonnes of potatoes could be stored in a $20 \mathrm{~m}^{3}$ capacity of cold storage constructed of polyurethane sheets (100 mm thick) and coupled with 2 tonnes of vapor using a compression refrigeration system (VRF technology), employing a $5 \mathrm{~kW}$ photovoltaic hybrid system.

- It is also concluded that cooling pads maintained the required storage temperature by charging and discharging during day- and nighttime, respectively, eliminating the nighttime operation of refrigeration machine due to less temperature difference. Therefore, integration of such cooling pads is useful technology for a cold storage system run by solar energy.

- This solar-hybrid technology can play a vital role in addressing the decentralized storage of various agricultural products to reduce losses with minimum energy requirements for the addition of value and generation of income.

In order to reduce food losses and to develop cold storage facilities, the following recommendations are made:

- The current system was developed for handling of a specific quantity of product (2 tonnes), showing a solar energy contribution of more than $70 \%$. Thus, in case of large commercial units, the scaled-up replications of such units would play a vital role to reduce the high operational cost. Therefore, it is recommended to scale up the system for commercial applications.

- The design and placement of the opening door is very important in terms of losses. We recommended that a separate chamber is added at the entrance to minimize these losses.

Author Contributions: Conceptualization, A.M., T.A. and W.A.; methodology, A.G. and A.U.M.; software, S.R. and W.A.; validation, A.M. and O.H.; formal analysis, T.A., W.A., A.G. and T.M.; investigation, W.A., A.G., S.R. and T.M.; resources, A.M. and O.H.; data curation, A.M., T.A. and W.A; writing—original draft preparation, A.M. and T.A.; writing—review and editing, W.A., M.S. and T.M.; visualization, A.U.M., M.S. and T.M.; supervision, A.M. and O.H.; project administration, A.M.; funding acquisition, A.M. All authors have read and agreed to the published version of the manuscript.

Funding: This work was supported by the Higher Education Commission (HEC) of Pakistan under its program "Technology Development Fund" (Project number TDF-082).

Institutional Review Board Statement: Not applicable.

Informed Consent Statement: Not applicable.

Data Availability Statement: Not applicable. 
Acknowledgments: This work was supported by the Higher Education Commission (HEC) of Pakistan under its program "Technology Development Fund" (Project number TDF-082).

Conflicts of Interest: The authors declare no conflict of interest.

\section{References}

1. Godfray, H.C.J.; Beddington, J.R.; Crute, I.R.; Haddad, L.; Lawrence, D.; Muir, J.F.; Pretty, J.; Robinson, S.; Thomas, S.; Toulim, C.; et al. Food security: The challenge of feeding 9 billion people. Science 2010, 327, 812-818. [CrossRef] [PubMed]

2. Maphosa, B. Investigation on Post-Harvest Processing of Fruits Using a Solar-Bio-Energy Hybrid Dryer 2020. North-West University South Africa Report. Available online: https:/ / repository.nwu.ac.za/bitstream/handle/10394/35592/Maphosa_B. pdf? sequence $=1$ (accessed on 30 September 2021).

3. Raza, H.M.U.; Ashraf, H.; Shahzad, K.; Sultan, M.; Miyazaki, T.; Usman, M.; Shamshiri, R.; Zhou, Y.; Ahmad, R. Investigating applicability of evaporative cooling systems for thermal comfort of poultry birds in Pakistan. Appl. Sci. 2020, 10, 4445. [CrossRef]

4. Lal Basediya, A.; Samuel, D.V.K.; Beer, V. Evaporative cooling system for storage of fruits and vegetables-A review. J. Food Sci. Technol. 2013, 50, 429-442. [CrossRef] [PubMed]

5. Olosunde, W.A.; Igbeka, J.C.; Olurin, T.O. Performance evaluation of absorbent materials in evaporative cooling system for the storage of fruits and vegetables. Int. J. Food Eng. 2009, 5, 1-15. [CrossRef]

6. Hasan, M.; Shang, Y.; Akhter, G.; Jin, W. Application of VES and ERT for delineation of fresh-saline interface in alluvial aquifers of Lower Bari Doab, Pakistan. J. Appl. Geophys. 2019, 164, 2200-2213. [CrossRef]

7. Hasan, M.U.; Malik, A.U.; Ali, S.; Imtiaz, A.; Munir, A.; Amjad, W.; Anwar, N. Modern drying techniques in fruits and vegetables to overcome postharvest losses: A review. J. Food Process. Preserv. 2019, 43, e14280. [CrossRef]

8. Hanif, S.; Sultan, M.; Miyazaki, T.; Koyama, S. Investigation of energy-efficient solid desiccant system for the drying of wheat grains. Int. J. Agric. Biol. Eng. 2019, 12, 221-228. [CrossRef]

9. Amjad, W.; Crichton, S.O.J.; Munir, A.; Hensel, O.; Sturm, B. Hyperspectral imaging for the determination of potato slice moisture content and chromaticity during the convective hot air drying process. Biosyst. Eng. 2018, 166, 170-183. [CrossRef]

10. Ramos, I.N.; Brandão, T.R.S.; Silva, C.L.M. Structural changes during air drying of fruits and vegetables. Food Sci. Technol. Int. 2003, 9, 201-206. [CrossRef]

11. Ajiboye, A.O.; Afolayan, O. The impact of transportation on agricultural production in a developing country: A case of kolanut production in Nigeria. Int. J. Agric. Econ. Rural Dev. 2009, 2, 49-57.

12. Sipahioglu, O.; Barringer, S.A. Dielectric properties of vegetables and fruits as a function of temperature, ash, and moisture content. J. Food Sci. 2003, 68, 234-239. [CrossRef]

13. Ali, S.D.; Ramaswamy, H.S.; Awuah, G.B. Thermo-physical properties of selected vegetables as influenced by temperature and moisture content. J. Food Process. Eng. 2002, 25, 417-433. [CrossRef]

14. Zhang, H.; Zhou, R.; Lorente, S.; Ginestet, S. Thermodynamic design of cold storage-based alternate temperature systems. Appl. Therm. Eng. 2018, 144, 736-746. [CrossRef]

15. Diaconu, B.M.; Varga, S.; Oliveira, A.C. Numerical simulation of a solar-assisted ejector air conditioning system with cold storage. Energy 2011, 36, 1280-1291. [CrossRef]

16. Ghafoor, A.; Rehman Tur Munir, A.; Ahmad, M.; Iqbal, M. Current status and overview of renewable energy potential in Pakistan for continuous energy sustainability. Renew. Sustain. Energy Rev. 2016, 60, 1332-1342. [CrossRef]

17. Sheikh, M.A. Energy and renewable energy scenario of Pakistan. Renew. Sustain. Energy Rev. 2010, 14, 354-363. [CrossRef]

18. Otanicar, T.; Taylor, R.A.; Phelan, P.E. Prospects for solar cooling-An economic and environmental assessment. Sol. Energy 2012, 86, 1287-1299. [CrossRef]

19. Wang, D.; Hu, L.; Liu, Y.; Liu, J. Performance of off-grid photovoltaic cooling system with two-stage energy storage combining battery and cold water tank. Energy Procedia 2017, 132, 574-579. [CrossRef]

20. Singh, P.L.; Jena, P.C.; Giri, S.K.; Gholap, B.S.; Kushwah, O.S. Solar-Powered Cold Storage System for Horticultural Crops. In Energy Environ; Springer: Berlin/Heidelberg, Germany, 2018; pp. 125-131.

21. Pinto, S.; Madhusudhan, A. Solar Powered Refrigeration System with Cold Bank. Indian J. Sci. Technol. 2016, 9, 1-5. [CrossRef]

22. Ul, N.; Rather, R.; Moses, S.; Sahoo, U.; Tripathi, A. Performance Evaluation of Hybrid Cold Storage using Solar \& Exhaust heat of Biomass Gasifier for Rural Development. IJRITCC 2017, 5, 563.

23. Zheng, L.; Zhang, W.; Liang, F. A review about phase change material cold storage system applied to solar powered airconditioning system. Adv. Mech. Eng. 2017, 9, 1-20. [CrossRef]

24. Ghafoor, A.; Munir, A. Design and economics analysis of an off-grid PV system for household electrification. Renew. Sustain. Energy Rev. 2015, 42, 496-502. [CrossRef]

25. Medford, A.J.; Lilliedal, M.R.; Jørgensen, M.; Aarø, D.; Pakalski, H.; Fyenbo, J.; Krebs, F. Grid-connected polymer solar panels: Initial considerations of cost, lifetime, and practicality. Opt. Express 2010, 18, A272-A285. [CrossRef]

26. Chourasia, M.K.; Goswami, T.K. Simulation of Transport Phenomena during Natural Convection Cooling of Bagged Potatoes in Cold Storage, Part II: Mass Transfer. Biosyst. Eng. 2006, 94, 207-219. [CrossRef]

27. Liu, Y.; Vittal, V.; Undrill, J.; Eto, J.H. Transient model of air-conditioner compressor single phase induction motor. IEEE Trans. Power Syst. 2013, 28, 4528-4536. [CrossRef] 
28. Evans, J.A.; Hammond, E.C.; Gigiel, A.J.; Fostera, A.M.; Reinholdt, L.; Fikiin, K.; Zilio, C. Assessment of methods to reduce the energy consumption of food cold stores. Appl. Therm. Eng. 2014, 62, 697-705. [CrossRef]

29. Razzaq, K.; Khan, A.S.; Malik, A.U.; Shahid, M.; Ullah, S. Role of putrescine in regulating fruit softening and antioxidative enzyme systems in 'Samar Bahisht Chaunsa'mango. Postharvest. Biol. Technol. 2014, 96, 23-32. [CrossRef]

30. Malik, A.U.; Singh, Z. Improved fruit retention, yield and fruit quality in mango with exogenous application of polyamines. Sci. Hortic. 2006, 110, 167-174. [CrossRef]

31. Khurana, S.M.P.; Minhas, J.S.; Pandey, S.K. The Potato: Production and Utilization in Sub-Tropics; Mehta Pub: New Delhi, India, 2003.

32. Amjad, A. Screening Potato Cultivars for Sugar Accumulation in Response to Cold Storage and Their Mitigation Through Reconditioning; University of Agriculture: Faisalabad, Pakistan, 2017. 